\title{
The COVID-19 Pandemic and Mental Health Symptoms Among US Adults
}

J Gen Intern Med 36(10):3285-8

DOI: $10.1007 / \mathrm{s} 11606-021-07046-3$

(C) Society of General Internal Medicine 2021

\section{INTRODUCTION}

Fear and stress related to the COVID-19 pandemic coupled with social isolation has contributed to symptoms of depression, anxiety, and insomnia. ${ }^{1}$ Older adults may be particularly vulnerable given their higher risk of mortality from COVID19 as well as the negative impact of mental health symptoms on management of chronic conditions. ${ }^{2}$ Our purpose was to sample adults about the effects of the pandemic on their mental health, hypothesizing that a majority of older respondents would report worsened symptoms during the pandemic.

\section{METHODS}

The University of Michigan National Poll on Health Aging is a survey of adults ages 50-80 years. The poll uses KnowledgePanel (Ipsos Public Affairs LLC), a probabilitybased web panel of the civilian, noninstitutionalized US population to generate a nationally representative sample. Demographic information collected among panel members is used to generate and adjust design weights to ensure panel respondents reflect the U.S. Census population estimates. ${ }^{3}$ The internet survey was fielded in January 2021; the response rate was $78 \%$. This study was approved by the University of Michigan institutional review board.

Along with demographics and self-reported health status, respondents were asked compared to before the pandemic, to rate their overall mental health, sleep, depression, and anxiety. Lastly, respondents were asked about strategies they have utilized since March 2020 to help address their mental health.

Perceived changes in overall mental health, sleep, depression, and anxiety following the start of the pandemic were assessed. The associations between respondent characteristics and symptom change were examined with logistic regression. Models were adjusted for age, sex, race/ethnicity, education, total annual household income, current employment status, and perceived physical health status. Strategies to address

No related papers have been published or submitted from this study.

Received May 17, 2021

Accepted July 14, 2021

Published online July 27, 2021 mental health were examined by demographic characteristics. Analyses used survey weights to draw national inferences and were performed using Stata version 15.1.

\section{RESULTS}

Among 2023 respondents aged 50-80 years, most reported their mental health as no worse than before the pandemic. However, $18.3 \%$ reported their mental health to be worse; $18.7 \%$ of respondents reported worse sleep, $18.9 \%$ worse depression, and $28.3 \%$ worse anxiety.

In adjusted analyses, several groups were more likely to report worse mental health including the following: females (AOR 1.75, 95\% CI 1.36-2.25), those with a bachelor's degree (AOR 2.00, 95\% CI 1.42-2.80), and respondents rating physical health as fair to poor (AOR 1.69, 95\% CI 1.20-2.38; Table 1). By contrast, respondents who were older were less likely to report worse mental health (AOR $0.58,95 \%$ CI 0.44 0.77). Findings by age were consistent for sleep, depression, and anxiety.

After March 2020, 29.0\% of respondents made a lifestyle change to address mental health. $12.7 \%$ discussed a new mental health concern with their primary care provider while $5.4 \%$ and $5.6 \%$ of respondents started seeing a mental health provider or adjusted/started a new medication. Making lifestyle changes to address mental health was more common among female, non-Hispanic Black, and Hispanic respondents (Table 2). Female respondents were significantly more likely to discuss such concerns with their primary care provider (AOR 1.78, 95\% CI 1.30-2.42) and consider medication treatment (AOR 1.79, 95\% CI 1.09-2.94).

\section{DISCUSSION}

While most US adults reported no change in their mental health, $20 \%$ reported that it worsened since the start of the pandemic. Female and more educated respondents reported higher odds of worse mental health, along with those with poor physical health. ${ }^{4}$ Younger respondents were more likely to report worse mental health, though employment status was not associated.

Respondents reported engaging in a variety of strategies to improve their mental health, with lifestyle change most commonly reported. Engagement in such activities was more common among female, non-Hispanic black, and Hispanic 


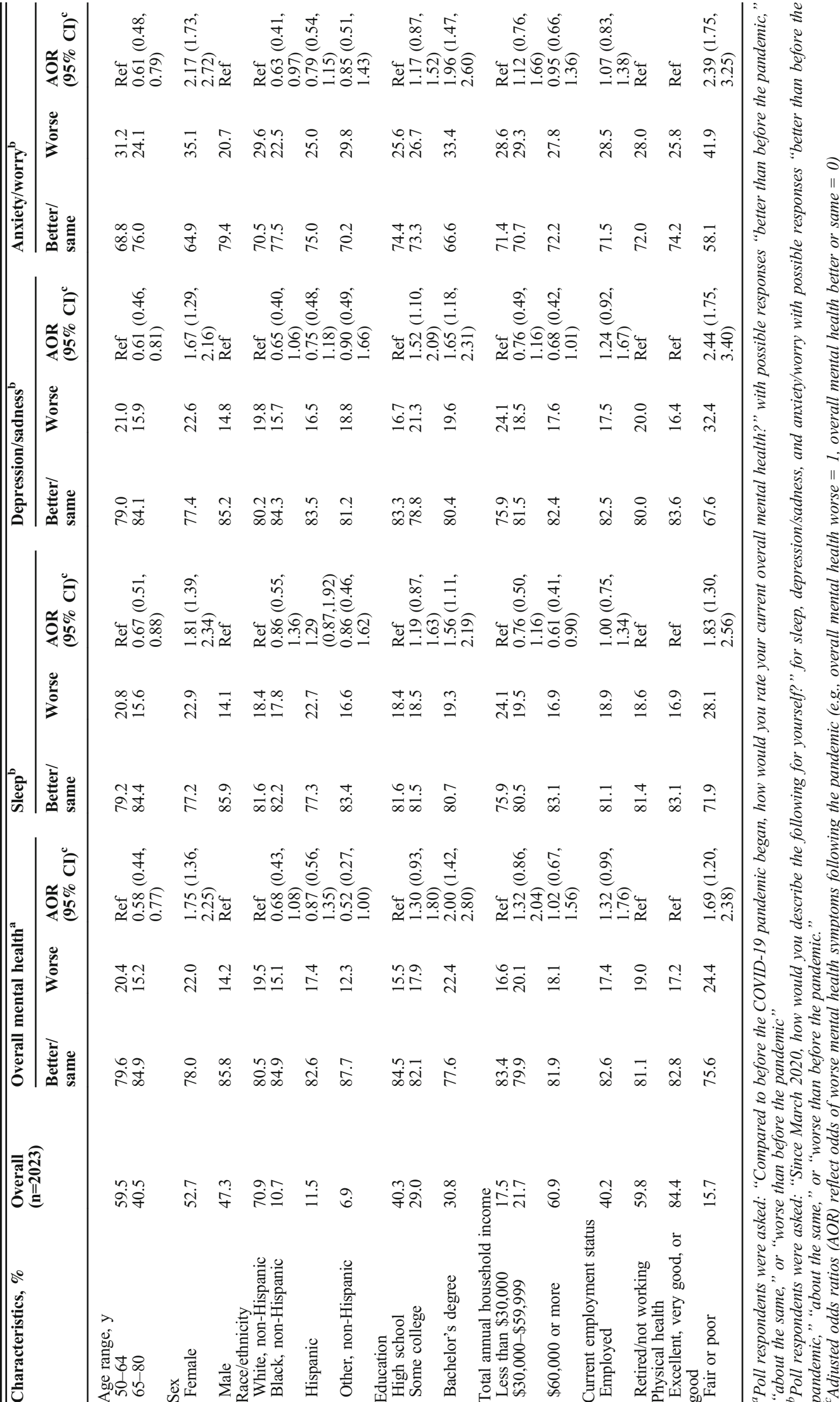


Table 2 Actions Taken to Address Mental Health During the COVID-19 Pandemic by Age, Sex, and Race/Ethnicity ${ }^{\mathrm{a}}$

\begin{tabular}{|c|c|c|c|c|c|c|c|c|c|c|c|c|}
\hline \multirow[t]{2}{*}{ Characteristics, \% } & \multicolumn{3}{|c|}{$\begin{array}{l}\text { Made a lifestyle change } \\
\text { (exercise, diet, meditation) }\end{array}$} & \multicolumn{3}{|c|}{$\begin{array}{l}\text { Discussed with primary } \\
\text { care provider }\end{array}$} & \multicolumn{3}{|c|}{$\begin{array}{l}\text { Adjusted or started new } \\
\text { medication }\end{array}$} & \multicolumn{3}{|c|}{$\begin{array}{l}\text { Started seeing a mental } \\
\text { health professional }\end{array}$} \\
\hline & Yes & No & $\begin{array}{l}\text { AOR } \\
(95 \% \text { CI })^{b}\end{array}$ & Yes & No & $\begin{array}{l}\text { AOR } \\
(95 \% \mathrm{CI})^{\mathrm{b}}\end{array}$ & Yes & No & $\begin{array}{l}\text { AOR } \\
(95 \% \text { CI })^{b}\end{array}$ & Yes & No & $\begin{array}{l}\text { AOR } \\
(95 \% \text { CI })^{b}\end{array}$ \\
\hline \multicolumn{13}{|l|}{ Age range, y } \\
\hline $50-64$ & 31.4 & 68.6 & Ref & 13.4 & 86.6 & Ref & 6.0 & 94.0 & Ref & 6.5 & 93.5 & Ref \\
\hline $65-80$ & 25.4 & 74.6 & $\begin{array}{l}0.79 \\
(0.63,1.00)\end{array}$ & 11.7 & 88.3 & $\begin{array}{l}0.75 \\
(0.53,1.05)\end{array}$ & 4.9 & 95.1 & $\begin{array}{l}0.60 \\
(0.36,0.99)\end{array}$ & 3.7 & 96.3 & $\begin{array}{l}0.52 \\
(0.31,0.88)\end{array}$ \\
\hline \multicolumn{13}{|c|}{$(0.00,1.00)$} \\
\hline Female & 33.4 & 66.6 & $\begin{array}{l}1.71 \\
(1.37,2.13)\end{array}$ & 15.8 & 84.2 & $\begin{array}{l}1.78 \\
(1.30,2.43)\end{array}$ & 7.2 & 92.8 & $\begin{array}{l}1.79 \\
(1.09,2.94)\end{array}$ & 6.4 & 93.6 & $\begin{array}{l}1.59 \\
(0.97,2.60)\end{array}$ \\
\hline $\begin{array}{l}\text { Male } \\
\text { Race/ethnicity }\end{array}$ & 24.0 & 76.0 & Ref & 9.2 & 90.8 & Ref & 3.7 & 96.3 & Ref & 4.2 & 95.8 & Ref \\
\hline $\begin{array}{l}\text { White, non- } \\
\text { Hispanic }\end{array}$ & 26.8 & 73.2 & Ref & 13.0 & 87.0 & Ref & 5.4 & 94.6 & Ref & 4.7 & 95.3 & Ref \\
\hline $\begin{array}{l}\text { Black, non- } \\
\text { Hispanic }\end{array}$ & 37.6 & 62.4 & $\begin{array}{l}1.63 \\
(1.15,2.32)\end{array}$ & 15.1 & 84.9 & $\begin{array}{l}1.00 \\
(0.60,1.67)\end{array}$ & 5.9 & 94.1 & $\begin{array}{l}0.87 \\
(0.41,1.86)\end{array}$ & 8.7 & 91.3 & $\begin{array}{l}1.67 \\
(0.87,3.32)\end{array}$ \\
\hline Hispanic & 34.1 & 65.9 & $\begin{array}{l}1.54 \\
(1.07,2.21)\end{array}$ & 10.5 & 89.5 & $\begin{array}{l}0.72 \\
(0.42,1.25)\end{array}$ & 4.5 & 95.5 & $\begin{array}{l}0.74 \\
(0.30,1.84)\end{array}$ & 7.0 & 93.0 & $\begin{array}{l}1.60 \\
(0.81,3.16)\end{array}$ \\
\hline $\begin{array}{l}\text { Other, non- } \\
\text { Hispanic }\end{array}$ & 29.6 & 70.4 & $\begin{array}{l}1.12 \\
(0.69,1.82)\end{array}$ & 9.5 & 90.5 & $\begin{array}{l}0.72 \\
(0.33,1.58)\end{array}$ & 9.1 & 90.9 & $\begin{array}{l}1.39 \\
(0.53,3.66)\end{array}$ & 4.2 & 95.8 & $\begin{array}{l}0.82 \\
(0.21,3.17)\end{array}$ \\
\hline
\end{tabular}

${ }^{a}$ The percentage of poll respondents who endorsed specific strategies in response to the following questions "Since March 2020, have you done any of the following for your mental health?": "Made a lifestyle change to improve my well-being (such as exercise, diet, meditation)?," "Discussed any new mental health concerns with your primary care provider?," "Started seeing a mental health professional (counselor, therapist, psychiatrist)?," and "Adjusted or started a new mental health medication?"

${ }^{b}$ Logistic regression was used to compare the particular strategies endorsed by age, sex, and racelethnicity. Adjusted odds ratios (AOR) reflect an increased likelihood of taking action to address mental health following the pandemic (e.g., yes $=1$, no $=0$ )

respondents. Increased use of mental health medications is consistent with reports from US prescription benefit plans demonstrating increased antidepressant and antianxiety prescribing during the pandemic. ${ }^{5}$

Study limitations include reliance on self-reported mental health symptoms rather than use of validated questionnaires and the potential for non-response bias, though analysis applied survey weights to account for this.

Given the increase in mental health symptoms during the pandemic, screening for symptoms and ensuring accessible treatment, including through telehealth, are essential even as the pandemic improves. ${ }^{6}$ Such treatment will be needed to help mitigate long-term emotional and physical effects of mental health symptoms during the pandemic and to restore functioning and quality of life for older adults.

Lauren B. Gerlach, DO, MS ${ }^{1,2}$

Erica Solway, $\mathrm{PhD}, \mathrm{MSW}, \mathrm{MPH}^{2}$

Donovan T. Maust, $M D, \mathrm{MS}^{1,2,3}$

Matthias Kirch, $M S^{2}$

Jeffrey T. Kullgren, MD, MS, $M P H^{2,3,4}$

Dianne C. Singer, $M P H^{2,5}$

Preeti N. Malani, $M D, M_{S} J^{2,4}$

${ }^{1}$ Department of Psychiatry, University of Michigan, Ann Arbor, MI, USA

${ }^{2}$ Institute for Healthcare Policy and Innovation, University of Michigan,

Ann Arbor, MI, USA

${ }^{3}$ Center for Clinical Management Research, Veterans Affairs Ann Arbor Healthcare System,

Ann Arbor, MI, USA
${ }^{4}$ Department of Internal Medicine, University of Michigan,

Ann Arbor, MI, USA

${ }^{5}$ Child Health Evaluation and Research Center, University of Michigan,

Ann Arbor, USA

Corresponding Author: Lauren B. Gerlach, DO, MS; Department of Psychiatry, University of Michigan, Ann Arbor, MI, USA (e-mail: glauren@umich.edu).

Author Contribution Drs. Gerlach and Malani had full access to all the data in the study and take responsibility for the integrity of the data and the accuracy of the data analysis.

Study concept and design: Gerlach, Solway, Kullgren, Singer, Malani Acquisition, analysis, or interpretation of data: all authors

Drafting of the manuscript: Gerlach, Maust

Critical revision of the manuscript for important intellectual content: All authors

Statistical analysis: Gerlach, Kirch

Obtaining funding: Malani

Administrative, technical, or material support: Solway, Kullgren, Singer, Malani

Supervision: Gerlach

Funding This work was supported by AARP, Michigan Medicine, and K23AG066864 (Dr. Gerlach) from the National Institute on Aging.

\section{Declarations:}

Conflict of Interest: Dr. Kullgren reports receiving consulting fees from SeeChange Health, HealthMine, and the Kaiser Permanente Washington Health Research Institute and honoraria from the Robert Wood Johnson Foundation, AbilTo, Inc., the Kansas City Area Life Sciences Institute, and the American Diabetes Association. All other authors report no disclosures. 
Disclaimer: The funding sources had no role in the design and conduct of the study; collection, management, analysis, and interpretation of the data; preparation, review, or approval of the manuscript; and decision to submit the manuscript for publication.

\section{REFERENCES}

1. Czeisler MÉ LR, Petrosky E, et al. Mental Health, Substance Use, and Suicidal Ideation During the COVID-19 Pandemic - United States, June 24-30, 2020. MMWR Morb Mortal Wkly Rep 2020;69:1049-1057.

2. Ganson KT, Weiser SD, Tsai AC, Nagata JM. Associations between Anxiety and Depression Symptoms and Medical Care Avoidance during COVID-19. J Gen Intern Med 2020;35(11):3406-3408.

3. KnowledgePanel: A Methodological Overview. Available at: https://www ipsos.com/sites/default/files/ipsosknowledgepanelmethodology. pdf. Accessed 1 Jun 2021.
4. Kaiser Family Foundation. Vaccine Monitor: Women and Younger Adults Hit Hardest by Mental Health Impacts Due to COVID-19. April 14, 2021. Available at: https://www.kff.org/coronavirus-covid-19/press-release/ vaccine-monitor-women-and-younger-adults-hit-hardest-by-mental-health-impacts-due-to-covid-19/. Accessed 14 April 2021.

5. America's State of Mind Report. Express Scripts. April 16, 2020. Available at: https://www.express-scripts.com/corporate/ americas-state-of-mind-report. Accessed 24 August 2020.

6. Busch AB, Sugarman DE, Horvitz LE, Greenfield SF. Telemedicine for treating mental health and substance use disorders: reflections since the pandemic. Neuropsychopharmacology. 2021;46(6):1068-1070. https:// doi.org/10.1038/s41386-021-00960-4.

Publisher's Note: Springer Nature remains neutral with regard to jurisdictional claims in published maps and institutional affiliations. 